\title{
Macrothink
}

\section{The Effects of a Token Economy System to Improve Social, Academic, and Behavior Skills with Children in KSA}

\author{
Ragea Mohammad Alqahtani \\ Associate Professor in Special Education, Faculty of Education, Najran \\ University-Saudi Arabia \\ P.O. Box 1988, Najran 61441, KSA
}

Tel: 966-540-226-220. E-mail: Ragea.edu.1979@gemail.com

Received: May 29, 2020 Accepted: June 20, 2020 Published: July 20, 2020

doi:10.5296/ijld.v10i3.17385 URL: https://doi.org/10.5296/ijld.v10i3.17385

\begin{abstract}
The study aimed to define the effect of a Token Economy System on improving social, academic, and behavior skills with children. The study used qualitative analysis method by using teacher's guide, questionnaire, and observational checklist. The sample of the study consisted of (40) male and female students in the age group (1-10) years. The results of the study showed that through qualitative studies of the methodology, it is clear that a symbolic economic system has a high impact on improving social, academic and behavioral skills with children. In light of the results, some recommendations were suggested.
\end{abstract}

Keywords: Token economy, social skills, academic skills, behavior skills, children

\section{Introduction}

Lots of teachers face challenges related to the management of students' behaviors. How students behave in classrooms dictate the kind of learning environment they are subjected to, the extent of their understanding, the success or failure of lesson delivery, and their academic achievements. Accordingly, selecting evidence-based techniques for managing the behavior of students becomes a priority for teachers before planning and executing lessons, particularly in classrooms comprising students with learning disabilities (Fain \& Duchaine, 2018). A token economy system is a type of positive reinforcement in which children obtain presents or rewards in the form of tokens for obeying the set regulations, and can earn motivating privileges or preferred products in exchange for such tokens. 


\section{Macrothink}

The token economy system has grown to become one of the leading and productive strategies for getting children to obey the rules. It mirrors the traditional reward systems in which children used to earn tokens during various assignments. Unlike preschoolers who are best suited for sticker charts, the token economy is useful for older children (Brophy, 2017). As an effective discipline tool, the positive reinforcement system helps teachers and parents to improve the social, academic, and behavioral skills of the children by getting them to follow instructions at school, doing their chores, and refraining from damaging items when hungry, among others (Sawalha \& Hawamdeh, 2010).

Children with learning problems tend to express social, academic, and behavioral challenges. Accordingly, there are likely to disturb their fellow learners to acquire their focus, not obeying the need to talk in turns, failing to complete class assignments, and generally 'being off tasks.' These inappropriate actions influence the performance of both teachers and students as they stimulate stress (Franklin \& Harrington, 2019). Moreover, such behaviors limit the time allocated to cover all the necessary curriculum benchmarks; because teachers spend considerable amounts of time addressing classroom disruptions, thus making it challenging to attain a desirable atmosphere.

\section{Importance of the Study}

Establishing the appropriate technique for managing social and academic behaviors within classrooms for reducing, and if possible, eliminating undesirable behaviors enhances students' academic achievements. It is beneficial to ensure that students follow classroom protocols that promote positive practices such as whispering during group discussions, raising hands to seek permission to speak, and being on tasks among others. Besides increasing students' success, adherence to classroom procedures, not only facilitates teachers' professional growth but also makes a positive impact on the school's culture. Various evidence-based approaches for managing classroom behavior among children, such as token economy, have positively impacted learners' behaviors in the classroom, leading to the improvements of their academic success, as well as attainment of positive social relationships with both fellow students and teachers. Therefore, it is important to undertake this study; as it will provide evidence-based results about how a token economy system affects students' social, academic, and behavioral skills.

\subsection{The Objective of the Study}

This study aims to explore the effect of a token economy system on social, academic, and behavior skills of school-going children.

\subsection{Research Questions}

i. What are the dominant disruptive behaviors in classrooms?

ii. How does a token economy assist in reducing disruptive behaviors among children?

\section{Literature Review}

Positive reinforcement strategies such as a token economy system, for controlling classrooms 
has been and continues to be deployed by many instructors. Scherzinger and Wettstein (2019) postulated that the behavior of children is often shaped by "social content of the environment within which they develop". In this regard, many behavioral challenges are worsened through different behavior-changing processes such as extinction, modeling, punishment, and reinforcement. Hence, educators are tasked with adjusting the learning environment; to minimize undesirable behaviors. Consequently, formulating effective transformation to the learning environment not only facilitates students' academic performance, but also enables both the teaching staff and student body; to establish a study environment characterized by productivity and mutual understanding.

Creating productive learning environments has been acknowledged as the key to delivering lessons successfully. This objective entails the search for avenues for limiting incidents of undesirable actions in classrooms. Shakespeare, Peterkin and Bourne (2018) affirm that such pursuits have identified the token economy to be effective in managing classroom behaviors. In addition to having acknowledged the threat posed by disruptive behaviors to the learning environment. Shakespeare and his colleagues (2018) study focused on what could be done to reduce undesirable behavior within the classrooms. They established that using a token economy offers a practical approach that assists in reducing inappropriate behaviors and enhancing academic performance and therefore it should be implemented in the teaching-learning system.

Social reinforcements help in shaping children behavior. They occur in various forms, including encouragement, gifting, appreciation, and providing attention. According to Franklin and Harrington (2019), teachers are aware of the fact that appreciating leaners for their positive behaviors makes them avoid searching for, and consider being involved in disruptive behavior. In other words, overlooking students increase their chances of disrupting lessons. Moreover, awarding children in order to motivate them to obtain optimal performance coupled with a strong desire towards it makes teachers deploy such an approach instead of merely emphasizing the primary stimuli for appropriate classroom behavior (Brophy, 2017). Therefore, by giving more care and attention to children, they will improve their class activities.

Educators have expressed interest in strengthening the association between the academic performance of students and their positive reinforcement. For example, Fain and Duchaine (2018) argue that many undesirable classroom behaviors, including talking out of turn and interfering with other students, can be addressed adequately through a token economy system to obtain desirable outcomes. Similarly, Shakespeare and his colleagues (2018) observe that using chips that could be exchanged with a trinket, whistle, and candy yielded positive impacts on the behavioral and academic skills of the subjects. Therefore, since a token economy acts as instant feedback, providing it in the form of rewards becomes more prominent than verbal appreciation.

Teachers must be aware of how to formulate an effective token economy system for children. It is recommended not to create complex reward systems that children do not understand, and teachers struggle to manage. In this context, it is advisable to have token economy systems, which are simple to enable both students and teachers to stay motivated. Several strategies can 
be used to create simple, motivating, and clear reward systems. Firstly, it is recommended to select at least three behaviors with varying performances. For instance, teachers can choose one practice in which the student is already excelling, another one that requires moderate improvement, and the challenging one (Robacker, Rivera \& Warren, 2016). Secondly, the desired behavior should be framed positively. In other words, rather than stating the unwanted actions, teachers should describe the appropriate goal that they want to be achieved so they can reward it with a token (Robacker et al, 2016). Doing so makes it easy to track and monitor a child's progress with the token economy strategy.

Additionally, how the token economy system is implemented informs its success or failure. In this regard, teachers need to device easy, practical ways of actualizing their reward systems. The following are some of the tried-and-tested implementation techniques. Firstly, if need be, the day should be broken down into smaller periods so that a child can be rewarded for achieving his / her respective targets for the morning, afternoon, and evening (Robacker et al, 2016). This approach is effective since it might be challenging and discouraging for some children to wait all day long to earn their rewards (Donahoe, 2005). Secondly, physically handing tokens to students whenever they meet their goals is vital because it facilitates the immediate provision of reinforcement for behaving well (Sarafino, 2004). Moreover, reward menus should be appealing to a variety of tokens. Therefore, creating exciting offers increases the chances that children will participate and thrive on meeting the desired goals (Rabian, 2005).

In sum, the literature informs that a productive token economy is one that gets the child excited and assists him / her always to stay motivated to improve his / her behaviors. The token economy should be kept positive, by ensuring that the child understands its role as one that revolves around rewarding desirable behavior, and not punishing him or her for making mistakes. Whereas such a reward system might require extra input at the beginning, it should spare the teacher extended periods spent disciplining the student in the end.

\section{Methodology}

This action research was based on qualitative design and data collected through an electronic survey.

\subsection{Sampling and Participants}

For this study, researcher selected participants from one stream of grade II classrooms. This class, which has exhibited the most undesirable behavioral patterns, was mainly picked on this basis. One teacher and all the (40) students in that class participated in the study. The students' ages were between (7) and (10) years. There were a total of (17) boys and (23) girls.

\subsection{Data Collection Tools}

Three appropriate data collection tools were used for the study. They include teacher's guide, questionnaire, and observational checklist. The function of the questionnaire was to gather varied responses for typical behavior patterns among students. The survey was administered at the beginning of the study. The teacher would use the observational checklist to observe 


\section{Macrothink}

International Journal of Learning and Development

ISSN 2164-4063 2020, Vol. 10, No. 3

learners in their ideal learning environment. This tool was critical to the study objective; because it enabled the teacher to observe students directly or indirectly with them being aware or not. It had eight aspects that guided the observation criteria. The checklist was used at the start and the end of the study. The guide was meant for offering reflective accounts derived from assessments of the observed and interpreted behaviors and events under investigation. It provided space for the teacher to observe and capture in writing both direct responses and non-verbal language, that communicated whether or not "learners enhanced their targeted practices, reduced their habits of talking out of turns, as well as whether students made efforts to build positive relationships with peers and teacher". The reflective guide was used throughout the study.

\section{Results}

Both the teacher's guide and observational checklist were used; to determine the dominant disruptive behaviors in classrooms before the implementation of the token economy intervention. Leaners were not only observed to establish the checklist criteria but also to collect data necessary for completing the observational checklist itself. Table (1) shows the results of various disruptive behaviors observed at the start of the study (before the implementation of the token economy intervention).

Table 1. Common Disruptive Behaviors among Students in Grade Two Classrooms

\begin{tabular}{|c|c|c|c|}
\hline \multirow[b]{2}{*}{$\begin{array}{l}\text { Type of Disruptive Behavior in the } \\
\text { Classroom }\end{array}$} & \multicolumn{3}{|c|}{ Number of Students (Frequency) } \\
\hline & $\begin{array}{l}\text { Girls } \\
\mathbf{N}=\mathbf{2 3}\end{array}$ & $\begin{array}{l}\text { Boys } \\
\mathbf{N}=17\end{array}$ & $\begin{array}{l}\text { Total } \\
\mathbf{N}=\mathbf{4 0}\end{array}$ \\
\hline Fighting & 6 & 8 & 14 \\
\hline Eating & 9 & 5 & 14 \\
\hline Talking without permission & 16 & 7 & 23 \\
\hline Quarreling & 5 & 8 & 13 \\
\hline Banging on desk & 5 & 11 & 16 \\
\hline Joking during lessons & 6 & 7 & 13 \\
\hline Frequent bathroom visits & 18 & 12 & 30 \\
\hline Disorderly conduct & 14 & 15 & 29 \\
\hline
\end{tabular}




\section{Macrothink}

International Journal of Learning and Development

ISSN 2164-4063 2020, Vol. 10, No. 3

Overall, results show that frequent bathroom visits (outside the official break hours) and general disorderly conducted are the highest disruptive behaviors among grade two students. On the other hand, joking during lessons, quarreling, eating, fighting, and banging on disks are the least disruptive behaviors among this age group. Figure (1) shows the proportion of students by gender who exhibits various disruptive behaviors before the implementation of the token economy system.

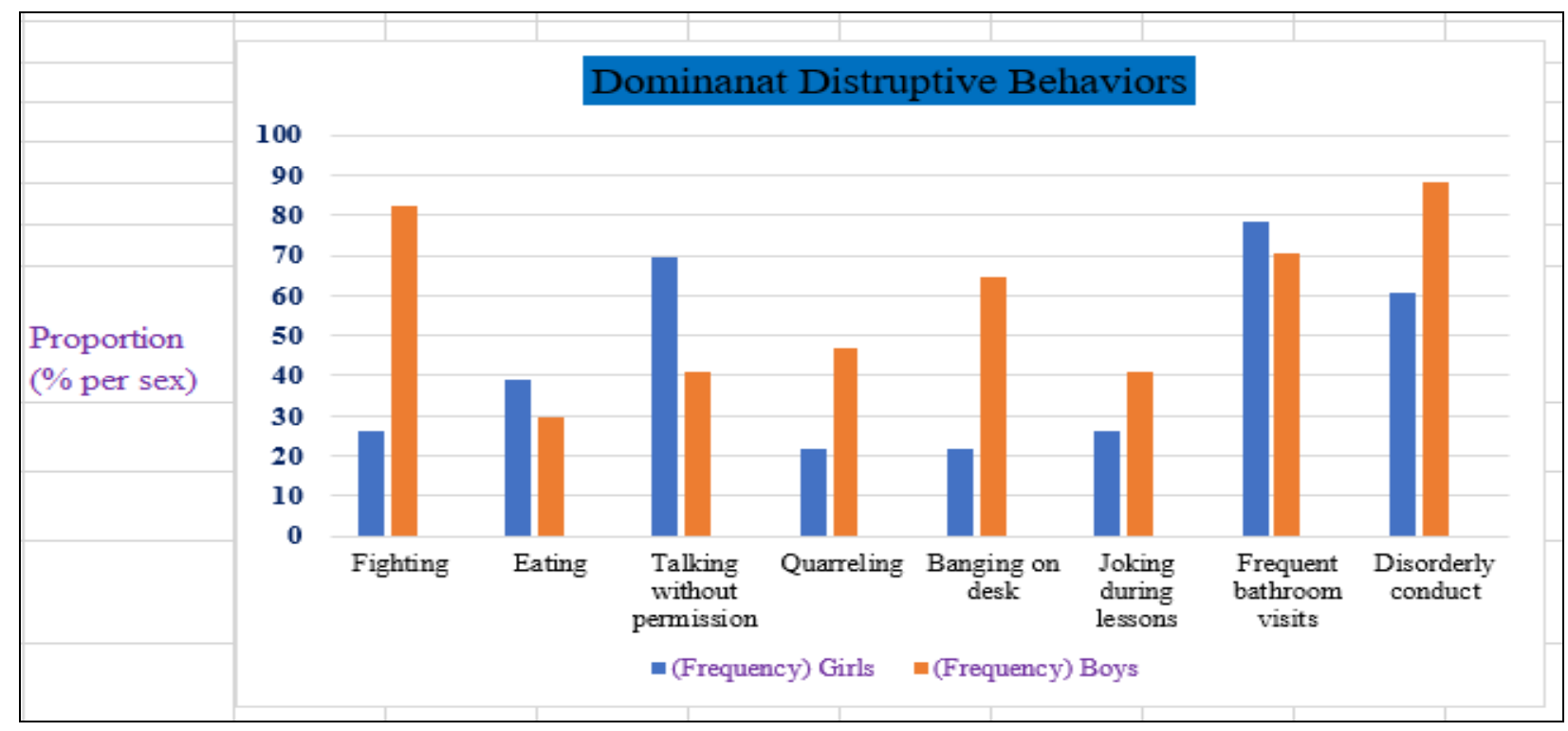

Figure 1. Proportion of Students Exhibiting Disruptive Behaviors (By Sex)

In terms of gender, girls expressed higher levels of talking without permission. Boys, on the other hand, led in fighting in the classroom, quarreling, banging on desks, and disorderly conduct. Little differences were observed regarding the rates of girls and boys that manifested behaviors such as eating in class, joking during lessons, and frequent visits to the bathroom.

Data regarding the research question on how a token economy assist in reducing disruptive behaviors among children was collected using both teacher's guide and observational checklist. 
Table 2. Comparative Table for the Dominant Disruptive Behaviors among Students Before and After the Use of Token Economy

\section{Number of Students}

Disruptive Behaviors

Before After

\begin{tabular}{lllll}
\cline { 2 - 4 } & Girls & Boys & Girls & Boys \\
\hline Fighting & 6 & 8 & 0 & 2 \\
Eating & 9 & 5 & 0 & 0 \\
Talking without permission & 16 & 7 & 9 & 4 \\
Quarreling & 5 & 8 & 3 & 5 \\
Banging on desk & 5 & 11 & 2 & 2 \\
Joking during lessons & 6 & 7 & 2 & 2 \\
Frequent bathroom visits & 18 & 12 & 4 & 3 \\
Disorderly conduct & 14 & 15 & 6 & 7 \\
\hline
\end{tabular}

Various positive changes were observed on the levels of disruptive behavior after the implementation of a token economy. For example, after using tokens, no student continued eating during the class. Similarly, no girl fought in class, with only $12 \%$ of the boys continued with this behavior as compared to $47 \%$ of the males exhibiting this behavior before the intervention. Significant improvements were also observed regarding behaviors, such as disorderly conduct $(60.8 \%$ vs $26.1 \%$ for girls and $88.2 \%$ vs. $41.2 \%$ for boys $)$, frequent bathroom visits $(78.3 \%$ vs. $17.4 \%$ for girls and $70.6 \%$ vs. $17.6 \%$ for boys $)$, joking during lessons $(26.1 \%$ vs. $8.7 \%$ for girls and $41.2 \%$ vs. $11.8 \%)$, and banging on desks $(21.7 \%$ vs. $8.7 \%$ for girls and $64.7 \%$ vs. $11.8 \%$ for boys).

\section{Discussion}

Based on the results, it is apparent that inappropriate classroom behaviors are common among school-going children, especially in the lower grades. These disruptive behaviors not only become the significant challenges that face instructors, but they are also likely to affect the student's social, academic, and behavioral skills in the long term. The participants demonstrated many disruptive behaviors that are likely to negatively affect their learning process as well as the teaching environment in their classrooms. However, through the 
implementation of a token economy, such as gifts, providing more attention, toys, and all manners of things that young children can exchange for their desired items, positive improvements were recorded across the dominant behaviors, showing that the use of a token economy assist students to achieve the targeted responses. A favorable learning environment is a recipe that improves student's engagement in academic activities. Moreover, extending the desirable behaviors that students demonstrate within the classroom to various spheres enables learners to improve their social skills.

\section{Conclusion}

The study revealed that disruptive behavior hinders the achievement of a favorable teaching and learning environment, and it can be minimized through a token economy system. The participants of the study expressed behavioral challenges, which were not recommendable for a classroom. Previous studies laid the basis that a token economy system can be used to minimize poor behaviors in classrooms, especially among children effectively. Such literature formed the foundation that guided this particular study in implementing a token economy among second grade students. Overall, findings in relation to disruptive practices after the use of a token economy showed proof that this intervention is effective in positively reinforcing students' behaviors. Therefore, the result implies that the token economy system can be used to decrease learner's levels of poor practice and motivate them to improve not only their academic performance but also their social and interaction skills.

\section{References}

Brophy, J. (2017). Fostering student learning and motivation in the elementary school classroom. Learning and motivation in the classroom, 283-306. https://doi.org/10.4324/9781315188522-15

Donahoe, J. (2005). Reintorcment In : Michel Hersen and Johan Rosqvist (eds). Encyclopedia of Behavior Modification and Cognitive Therapy. Adult Clineal Applications, 1, 472-476 .

Fain, A. \& Duchaine, E. (2018). Classroom management: Strategies for all teachers. From Head to Heart: High Quality Teaching Practices in the Spotlight, 75.

Franklin, H., \& Harrington, I. (2019). A review into effective classroom management and strategies for student engagement: Teacher and student roles in today's classrooms. Journal of Education and Training Studies, 7(12), 1-12. https://doi.org/10.11114/jets.v7i12.4491

Rabian, D. (2005). Premack Principle: In: Michel Hersen, Alanm. Gross and Rorands. Derbman (eds). Ency Ecopedaia of Behave or Modification and Cognitive Therapy. Child Clinical Applicatiotiors, 2, 966-968.

Robacker, C., Rivera, C., \& Warren, S. (2016). A token economy made easy through ClassDojo. Intervention in School and Clinic, 52(1), 39-43. https://doi.org/10.1177/1053451216630279

Sarafino, E. (2004). Behavior Modification: Principles of Behavior Change. Long Grove: 


\section{Macrothink \\ International Journal of Learning and Development \\ ISSN 2164-4063 2020, Vol. 10, No. 3}

Waveland Press, Inc.

Sawalha, M., \& Hawamdeh, M. (2010). Psychology of socialization: Theory and practice. Irbid: University Student Library.

Scherzinger, M., \& Wettstein, A. (2019). Classroom disruptions, the teacher-student relationship and classroom management from the perspective of teachers, students and external observers: A multimethod approach. Learning Environments Research, 22(1), 101-116. https://doi.org/10.1007/s10984-018-9269-x

Shakespeare, S. Peterkin, V., \& Bourne, P. (2018). A token economy: An approach used for behavior modifications among disruptive primary school children. MOJ Public Health, 7(3), 89-99. https://doi.org/10.15406/mojph.2018.07.00212

\section{Copyright Disclaimer}

Copyright for this article is retained by the author(s), with first publication rights granted to the journal.

This is an open-access article distributed under the terms and conditions of the Creative Commons Attribution license (http://creativecommons.org/licenses/by/4.0/). 